\title{
ALTERAÇÕES BIOgUIMICAS POST-MORTEM DE MATRINXÃ Brycon cephalus (GÜNTHER, 1869) PROCEDENTE DA PISCICULTURA, MANTIDO EM GELO'
}

\author{
Gilvan Machado BATISTA², Edson LESSI ${ }^{3, *}$, Makie KODAIRA ${ }^{4}$, Paulo de Tarso FALCÃO ${ }^{3}$
}

\begin{abstract}
RESUMO
No presente trabalho, foram estudadas as alterações bioquímicas post-mortem que ocorreram em matrinxã Brycon cephalus (Günther, 1869) procedente da piscicultura e mantido em gelo em Manaus - AM. Foi determinado o tempo de estocagem em gelo por meio das avaliações sensoriais físicas e gustativas, das análises de pH, Nitrogênio das Bases Voláteis Totais (N-BVT) e bacteriológicas durante 29 dias. Foram determinados os índices de rigor-mortis, as concentrações de ATP e seus produtos de degradações e o valor K. De acordo com a composição química, o peixe foi classificado como "semi-gordo". Os peixes entraram em rigor-mortis aos 75 minutos após a morte por hipotermia, tendo permanecido durante 10 dias. As avaliações sensoriais (físicas e gustativas) mostraram que os peixes apresentaram condição de consumo até 26 dias. As análises de ATP e de seus produtos de degradação mostraram que a referida espécie foi considerada formadora de inosina (HxR), nas condições de experimento. O valor $\mathrm{K}$ mostrou que os exemplares de matrinxãs permaneceram "muito frescos" até 16 dias de estocagem em gelo, concordante com a avaliação sensorial gustativa.

Palavras-chave: rigor-mortis; avaliação sensorial; nucleotídeos; índice de frescor; tempo de vida-útil.
\end{abstract}

\section{SUMMARY}

POST-MORTEM BIOCHEMICAL ALTERATIONS IN AQUACULTURED MATRINXÃ FISH Brycon cephalus (GÜNTHER, 1869) WHEN STORED ON ICE. Post-mortem biochemical alterations in aquacultured matrinxã fish Brycon cephalus (Günther, 1869) when stored on ice in Manaus-AM, were studied in this paper. The storage time on ice was determined through tasting and physical sensory evaluations, $\mathrm{pH}$, total volatile bases nitrogen (TVB-N) and bacteriological analyses during 29 days. Rigor-mortis index, ATP-related compounds and K value were also determined. Chemical composition demonstrated that fish was classified as "semi-fat". The specimens presented rigormortis 75 minutes after death caused by hypothermia and remained that way for 10 days. Shelf life time on ice was 26 days, according to sensory evaluations, pH, TVBN determinations and bacteriological analyses. ATP-related compounds pointed out that the referred species was considered to be inosine (HxR) forming, in experimental conditions. The $\mathrm{K}$ value pointed out that matrinxã specimens remained "quite fresh" up to 16 days storage time on ice corroborating the sensory, tasting evaluation.

Keywords: fish rigor-mortis; sensory evaluation; nucleotides; freshness index; shelf life.

\section{1 - INTRODUÇÃO}

Poucos autores têm se dedicado a estudar o acompanhamento da deterioração, ou seja, a conservação dos peixes tropicais de água doce em gelo, avaliando as alterações sensoriais, bioquímicas e microbiológicas.

O manuseio e a conservação incorretamente aplicados durante a captura e comercialização representam os principais problemas para manter a qualidade do pescado, e, atualmente, continuam sendo motivo de pesquisa. KODAIRA [21] descreveu as condições do manuseio e transporte de peixes frescos comercializados na Venezuela, mostrando a importância do conhecimento do rigor-mortis, como fator que pode afetar as características do pescado, quando este se apresenta em estresse e as alterações que podem ocorrer nas características sensoriais, químicas e microbiológicas no tambaqui Colossoma macropomum (Cuvier, 1818).

\footnotetext{
Recebido para publicação em 07/01/2003. Aceito para publicação em 25/10/2004 (001043).

2. Faculdade de Farmácia - Universidade Federal do Amazonas, Rua Alexandre Amorim, $n^{\circ}$ 330, Aparecida - Manaus-AM. E-mail: gilvan.mb@ig.com.br

3. Instituto Nacional de Pesquisas da Amazônia, Coordenação de Pesquisas em Tecnologia de Alimentos - Av. André Araújo, $n^{\circ}$ 2936, Caixa Postal 478, CEP 69011-970. E-mail: elessi@inpa.gov.br

4. Instituto de Ciências e Tecnologia-Universidade Central da VenezuelaCaracas.

* A quem a correspondência deve ser enviada.
}

ALMEIDA [2] realizou pesquisas sobre as alterações post-mortem em tambaqui Colossoma macropomum (Cuvier, 1818), procedente de piscicultura e mantido em gelo em Manaus - AM e observou que esta espécie apresentou condição de consumo até 43 dias, sendo 22 dias em primeira qualidade, demonstrando assim que pode ser comercializada e transportada por longas distâncias no mercado nacional e para a exportação.

Nesse trabalho, a pesquisa direcionou-se para o estudo das alterações bioquímicas post-mortem de matrinxã Brycon cephalus (Günther, 1869), cujos espécimes foram capturados diretamente do criatório e conservados entre camadas de gelo. Em contrapartida, os peixes procedentes dos rios, que são comercializados nas feiraslivres de Manaus vêm de longas distâncias, viajando em embarcações pesqueiras chamadas de "geleiras", onde são armazenados inadequadamente em grandes urnas que variam de um a três metros de profundidade, comprometendo assim a qualidade dos peixes.

O objetivo desta pesquisa foi acompanhar por meio de análises bioquímicas, físico-químicas, sensoriais e microbiológicas as alterações post-mortem de matrinxã Brycon cephalus (Günther, 1869) procedente da piscicultura, mantido em gelo em Manaus-AM.

\section{2 - MATERIAIS E MÉTODOS}

Utilizando rede de arrasto, foram capturados 113 espécimes de matrinxãs Brycon cephalus (Günther, 1869), criados em canal de barragem com água branca, em 
um sítio localizado a $110 \mathrm{Km}$ de Manaus pela estrada AM-010. Para as análises da pesquisa, 07 espécimes foram utilizados para se determinar o índice de rigormortis; 17 espécimes para se determinar a concentração de nucleotídeos e os demais para avaliação sensorial, determinação dos valores de $\mathrm{pH}$, Nitrogênio das Bases Voláteis Totais (N-BVT), contagem total de mesófilos, psicrotróficos e de psicrófilos e para determinação da composição centesimal do músculo do peixe.

Os espécimes de matrinxãs, após a captura, foram sacrificados por hipotermia, colocados entre camadas de gelo em caixas de polietileno expandido e, posteriormente, transportados para a Planta Piloto de Pescado da Coordenação de Pesquisas em Tecnologia de Alimentos (CPTA/INPA) em Manaus - AM.

O peso de cada espécime foi medido com auxílio de balança e o comprimento padrão foi medido com auxílio de ictiômetro.

A composição centesimal no músculo de matrinxã Brycon cephalus (Günther, 1869) foi determinada de acordo com as normas analíticas do INSTITUTO ADOLFO LUTZ [17] e as técnicas da AOAC [4]. O cálculo do valor calórico por $100 \mathrm{~g}$ de músculo foi realizado utilizando os fatores de Atwater (protídeos 4,0, carboidratos 4,0, lipídios 9,0).

Após a morte, os sete espécimes de matrinxãs foram identificados com etiquetas. O indice de rigor-mortis foi determinado nestes peixes a cada 15 minutos, com o propósito de identificar o início da entrada em rigor, do rigor total e, diariamente, até a resolução do rigor, segundo a metodologia descrita por BITO et al. [6], ilustrado na Figura 1 e calculado segundo a equação:

$\mathrm{IR}=\frac{\mathrm{D}-\mathrm{D}_{0}}{\mathrm{D}_{0}} \times 100$

Onde,

IR = Îndice de Rigor

$\mathrm{D}_{0}=$ Distância inicial entre a superfície da mesa e a base da nadadeira caudal

$\mathrm{D}$ = Distância final entre a superfície da mesa e a base da nadadeira caudal

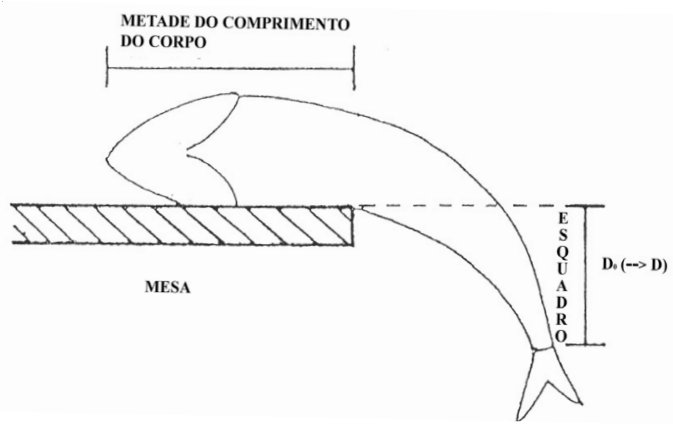

FIGURA 1. Determinação do índice de rigor-mortis do peixe, segundo BITO et al. [6]. " $\mathrm{D}_{\text {o }}$ " representa a distância da base da nadadeira caudal em relação à posição horizontal do pré-rigor do peixe na mesa. Com o aumento do rigor a distância "D" diminui e alcança zero em rigor pleno.

Fonte: IWAMOTO et al. [18].
A avaliação sensorial física foi realizada, em triplicata, no primeiro dia de estocagem em gelo e a cada três dias por uma equipe de 3 avaliadores treinados, utilizando uma tabela de avaliação sensorial baseada na tabela proposta pela Torry Research Station Aberdeen, Escócia [7] para o bacalhau e na tabela utilizada pela FAO, no curso FAO/DANIDA [14]. A avaliação sensorial gustativa foi realizada simultaneamente utilizando a tabela descrita em BURGESS et al. [8], modificada por ALMEIDA [2].

As análises de $\mathrm{pH}$ e a determinação do Nitrogênio das Bases Voláteis Totais foram realizadas de acordo com as normas analíticas do INSTITUTO ADOLFO LUTZ [17].

As contagens de bactérias na pele dos peixes foram realizadas no primeiro dia de conservação em gelo e a cada 3 dias utilizando "Swabs" (Zaragatoas) de algodão, aplicados nas partes laterais de cada amostra de pescado, conforme trabalhos de LEITÃO, TEIXEIRA FILHO \& BALDINI [22] e HUSS [15].

As concentrações de trifosfato de adenosina (ATP) e seus produtos degradados difosfato de adenosina (ADP), monofosfato de adenosina (AMP), monofosfato de inosina (IMP), inosina (HxR) e hipoxantina $(\mathrm{Hx})$ foram determinadas após a morte dos peixes, a cada 30 minutos até um período de $3 \mathrm{~h}$ e, posteriormente, com $6 \mathrm{~h}, 12 \mathrm{~h}, 24 \mathrm{~h} \mathrm{e}$ a cada 3 dias, conforme a metodologia descrita por IWAMOTO et al. [19] e VALLS, BELLO \& KODAIRA [29].

$\mathrm{O}$ valor $\mathrm{K}$ foi determinado pela razão entre a quantidade total de HxR e Hx e a quantidade total de ATP e seus produtos de degradação no músculo, segundo a equação descrita por SAITO, ARAI \& MATSUYOSHI [26], no mesmo intervalo de tempo descrito acima:

$K(\%)=\frac{[\mathrm{HxR}]+[\mathrm{Hx}]}{[\mathrm{ATP}]+[\mathrm{ADP}]+[\mathrm{AMP}]+[\mathrm{IMP}]+[\mathrm{HxR}]+[\mathrm{Hx}]} \times 100$

Para análise estatística foi utilizado o programa “Statistica 6.0". Foi realizada uma regressão linear simples, usando o $\mathrm{pH}$ e o valor $\mathrm{K}$ como variáveis respostas e o tempo como variável explicativa, segundo CHATTERJEE \& PRICE [9].

Para descrever a relação entre a avaliação sensorial (física e gustativa) e o tempo de estocagem em gelo foi utilizado o modelo não-linear quadrático descrito:

Avaliação Sensorial $=\beta_{0}+\beta_{1}$ tempo $+\beta_{2}$ tempo $^{2}+\varepsilon$

Onde,

$\beta_{0}=$ Intercepto

$\beta_{1}=$ Coeficiente Parcial Linear da Regressão

$\beta_{2}=$ Coeficiente Parcial Quadrático da Regressão

$\varepsilon=$ Termo de Resíduo N $\left[0, \sigma^{2}\right]$

\section{3 - RESULTADOS E DISCUSSÃO}

Os espécimes de matrinxãs Brycon cephalus (Günther, 1869) procedentes da piscicultura com 11 
meses de idade, mantidos em gelo, apresentaram médias de peso $1,23 \mathrm{~kg}( \pm 0,0894)$ e de comprimento padrão $34,7 \mathrm{~cm}( \pm 1,23)$.

\section{1 - Análise de composição química}

Os resultados obtidos na determinação da composição centesimal do músculo de matrinxã estão apresentados na Tabela 1.

Analisando os valores de umidade e de gordura, pode-se observar que a espécie Brycon cephalus, oriunda de piscicultura, pode ser classificada como semigorda, segundo ACKMAN [1] que cita um limite de variação do teor de gordura entre 4,0 e 8,0\%.

A quantidade de proteína determinada está de acordo com os valores da literatura, o peixe pode ser considerado boa fonte de proteína de alto valor biológico, porque apresenta todos os aminoácidos essenciais em proporções balanceadas, indispensáveis ao crescimento e desenvolvimento do corpo humano [5].

TABELA 1. Composição centesimal do músculo de matrinxã Brycon cephalus (Günther, 1869) procedente da piscicultura e mantido em gelo em Manaus - AM.

\begin{tabular}{lc}
\hline Determinações & Teores $(\mathrm{g} / 100 \mathrm{~g})$ \\
\hline UMIDADE & $72,3 \pm 0,1^{\mathrm{a}}$ \\
EXTRATO ETÉREO & $7,5 \pm 0,1^{\mathrm{a}}$ \\
PROTEÍNAS & $18,4 \pm 0,5^{\mathrm{a}}$ \\
CINZA & $0,9 \pm 0,0^{\mathrm{a}}$ \\
NIFEXT & $0,8^{\mathrm{b}}$ \\
VALOR CALÓRICO (KCal/100g) & 144,2 \\
\hline
\end{tabular}

(a) Valor médio de triplicata (b) Determinado por diferença

\section{2 - Análise do índice de rigor-mortis}

A Figura 2 mostra os resultados da determinação do índice de rigor-mortis em matrinxã Brycon cephalus (Günther, 1869), procedente da piscicultura e mantido em gelo. Após a morte dos peixes por hipotermia, os espécimes de matrinxãs apresentaram o corpo totalmente flácido, com a metade do comprimento do corpo inclinado, ou seja, zero por cento de rigor. Com $15 \mathrm{mi}$ nutos de permanência em gelo, foi observado o início do rigor-mortis cuja média do índice de rigor calculado foi de $17,65 \%( \pm 6,79)$ e os peixes apresentaram $100 \%$ de rigor aos 75 minutos após a morte. A resolução do rigor-mortis dos espécimes ocorreu após 10 dias, apresentando média de inclinação de $88,07 \%( \pm 10,22)$ de rigor e atingindo $75,03 \%( \pm 5,23)$ com 17 dias de estocagem em gelo.

AMLACHER [3] relata que o rigor-mortis pré-determina decisivamente a vida-de-prateleira de peixe fresco. Quando é prolongado no tempo, por meio de um atraso no seu início retarda a multiplicação de bactérias do peixe.

O rigor-mortis ocorre em músculo de peixe paralelamente à redução da quantidade de ATP presente no músculo, ou seja, está condicionado à degradação de
95\% do ATP no músculo e também à degradação do glicogênio a ácido lático.

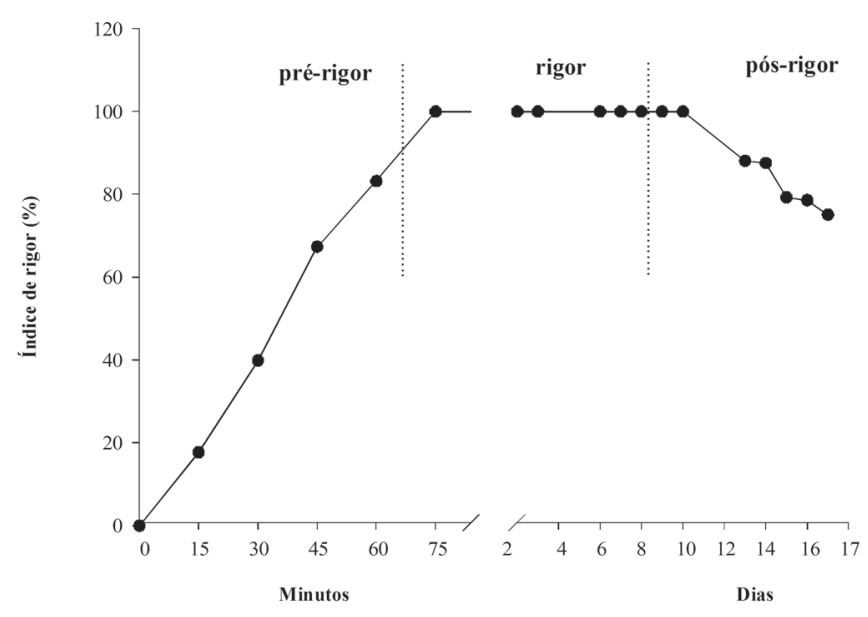

FIGURA 2. Determinação do índice de rigor-mortis em matrinxã Brycon cephalus (Günther, 1869) procedente da piscicultura, mantido em gelo durante 17 dias em Manaus AM.

Reações de "cold shock" têm sido observadas em espécies de peixes tropicais [2, 10, 24]. LESSI et al. [23] observaram que o músculo de matrinxãs jovens Brycon cephalus (Günther, 1869) criados em Manaus e armazenados em gelo, iniciou a contração muscular imediatamente após a morte por hipotermia e alcançando contração total em menos de 3 horas, coincidindo com a redução total do ATP do músculo. Esses autores citam que o curto período de pré-rigor, causado possivelmente pela degradação de ATP e a duração do rigor total de 4 dias podem ser características especiais dessa espécie de criatório e/ou do tamanho do peixe. Apoiado nesse estudo, os exemplares de matrinxãs desta pesquisa apresentaram o fenômeno rigor-mortis nas condições experimentais estabelecidas.

\section{3 - Análise sensorial física}

De acordo com os resultados da avaliação sensorial física mostrados na Figura 3, os exemplares de matrinxãs permaneceram com classe A (especial) durante 13 dias de conservação em gelo com média de 20,3 pontos $( \pm 0,57)$. Até o $23^{\circ}$ dia permaneceram com classe B (boa qualidade) alcançando média de 14,3 pontos $( \pm 0,35)$. No $29^{\circ}$ dia, apresentaram qualidade de consumo corrente (classe C) com média de 8,7 pontos $( \pm 2,52)$. No entanto, apesar de receberem a classificação (C), foram considerados "não aptos para o consumo", apresentando aparência física geral desagradável e odor azedo, mas mesmo assim, a média obtida pelas três avaliações alcançou 8,7 pontos e não um valor menor que 6, como estabelecido na tabela de avaliação sensorial para rejeitar o pescado.

Os resultados da avaliação sensorial mostraram que a tabela de avaliação utilizada não foi adequada aos exemplares de matrinxãs estudados nesta pesquisa, porque com 29 dias de conservação em gelo os peixes já apresentavam-se "não aptos para o consumo". 




FIGURA 3. Avaliação sensorial das características físicas de matrinxã Brycon cephalus (Günther, 1869) procedente da piscicultura, mantido em gelo durante 29 dias em Manaus - AM.

FALCÃO, LESSI \& LEITÃO [13] estudaram a deterioração do jaraqui Semaprochilodus insignis (Schomburgk, 1841) capturado em três rios de água doce no Estado do Amazonas e conservado em gelo, por meio da análise bacteriológica e da avaliação sensorial física. Esta última análise revelou que os peixes procedentes dos rios Manacapuru, Nhamundá e Tapauá tiveram vida-de-prateleira até 28,5, 20,5 e 25,5 dias, respectivamente. Os autores observaram também que não houve correlação significativa entre a contagem bacteriológica e a avaliação sensorial.

ALMEIDA [2] estudou as alterações post-mortem em Colossoma macropomum (Cuvier, 1818) procedente da piscicultura e conservado em gelo em Manaus-AM. De acordo com os resultados obtidos por meio da avaliação organoléptica, essa espécie teve vida-de-prateleira até 43 dias de estocagem em gelo, demonstrando que os peixes de criatórios de clima tropical de água doce apresentam vida-de-prateleira mais prolongada do que as espécies de peixes de clima temperado e frio. Os resultados da avaliação sensorial mostraram que os espécimes de matrinxãs apresentaram tempo de vida- útil até 26 dias de estocagem em gelo, sendo 13 dias em primeira qualidade; naturalmente auxiliado no manejo adequado durante a captura e a conservação dos peixes em gelo aplicada corretamente durante todo o período de estocagem. Houve correlação significativa $(r=0,96)$ entre os pontos de avaliação sensorial e o tempo de conservação em gelo, sendo considerado um bom critério para avaliação do frescor de matrinxã procedente da piscicultura e mantido em gelo.

\section{4 - Análise sensorial gustativa}

Os resultados obtidos da avaliação sensorial gustativa, a partir de músculo cozido de matrinxã Brycon cephalus (Günther, 1869), estão apresentados na Figu- ra 4. De acordo com os avaliadores, a referida espécie alterou-se levemente até 20 dias de estocagem em gelo, analisando o odor, o sabor e a textura do músculo do peixe. Sendo assim, recebeu classe A (especial) durante o período de 20 dias de estocagem em gelo, tendo passado para classe B (boa qualidade) quando atingiu 9,0 pontos na tabela de avaliação e, quando atingiu 6,0 pontos passou para classe $\mathrm{C}$ (qualidade de consumo corrente).

Com 29 dias de estocagem em gelo, o peixe foi considerado "impróprio para o consumo", o que deveria ocorrer quando atingisse 3,0 pontos. De acordo com as observações desta pesquisa, no final do período de 29 dias de conservação em gelo, o peixe apresentou sabor fortemente estranho, amargo, a textura permanecia pouco mole e odores estranhos podiam ser sentidos.

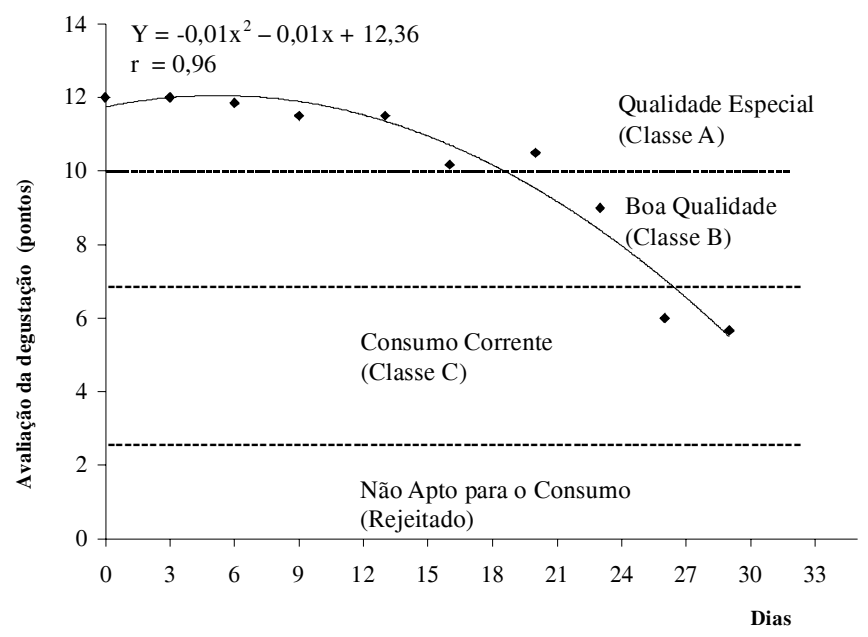

FIGURA 4. Avaliação sensorial gustativa do músculo cozido de matrinxã Brycon cephalus (Günther, 1869) procedente da piscicultura, mantido em gelo durante 29 dias em Manaus - AM.

Portanto, a avaliação sensorial gustativa do músculo cozido de matrinxã não acompanhou os limites estabelecidos pela tabela utilizada, sugerindo a necessidade de elaboração de tabela de avaliação sensorial adequada aos nossos peixes tropicais de água doce. No entanto, os resultados concordaram com a análise do valor $\mathrm{K}$.

ALMEIDA [2] observou, por meio da avaliação sensorial gustativa, que o tambaqui Colossoma macropomum (Cuvier, 1818), procedente de piscicultura e conservado em gelo em Manaus-AM, apresentou condição de consumo até 43 dias de estocagem em gelo, alcançando média de 6 pontos na tabela de avaliação sensorial. A autora cita que a tabela utilizada também não se mostrou adequada para os critérios de avaliação e, mesmo assim, o teste de gustação realizado ao longo de sua pesquisa foi considerado bom critério de frescor, devido ao elevado coeficiente de correlação calculado $(r=0,95)$. De acordo com o modelo não-linear utilizado para relacionar a variável "avaliação gustativa" 
com o "tempo de estocagem" apresentado na Figura 4, esperava-se que os exemplares de matrinxãs, procedentes da piscicultura e mantidos em gelo não estivessem aptos para o consumo com 35 dias de estocagem. Os valores de avaliação sensorial gustativa do músculo cozido de matrinxã ajustaram-se numa regressão não-linear simples, com coeficiente de correlação nãolinear bastante elevado $(r=0,96)$.

\section{5 - Análise de pH}

De acordo com os resultados apresentados na Figura 5, o pH determinado no músculo de matrinxã decresceu durante os 6 primeiros dias de estocagem em gelo, alcançando valor médio de 6,19. As avaliações sensoriais (física e gustativa) demonstraram que os peixes estavam com classe A ou qualidade especial (Figuras $3 e$ 4). Porém, após este período de estocagem, o $\mathrm{pH}$ começou a aumentar e alcançou 6,37 $( \pm 0,0)$ aos 29 dias de conservação.

Segundo HUSS [15], o pH do tecido muscular do peixe vivo é aproximadamente 7,0. Nos primeiros dias após a morte, devido à formação anaeróbica de ácido lático a partir de glicogênio, o $\mathrm{pH}$ do músculo decresce concomitantemente. No bacalhau de águas frias, o $\mathrm{pH}$ diminui de 6,8 a 6,1-6,5. Durante as alterações que ocorrem no músculo do peixe conservado em gelo, o $\mathrm{pH}$ é mais ou menos constante ou levemente aumentado devido à formação de compostos básicos.

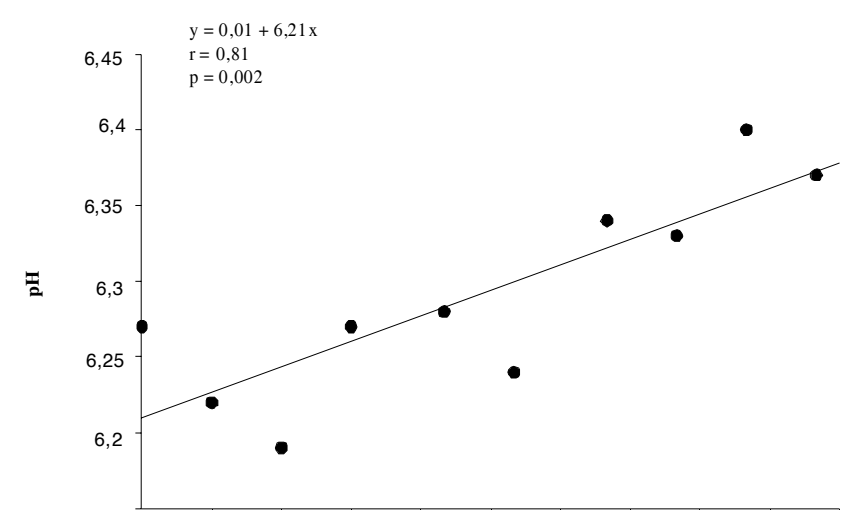

FIGURA 5. Determinação de pH no músculo de matrinxã Brycon cephalus (Günther, 1869) procedente da piscicultura, mantido em gelo durante 29 dias em Manaus - AM.

ALMEIDA [2] observou que os resultados de $\mathrm{pH}$ determinados em músculo de tambaqui Colossoma macropomum (Cuvier, 1818) procedente de piscicultura e conservado em gelo em Manaus-AM, demonstraram variações médias de 6,07 a 6,66 durante 49 dias de estocagem em gelo. Observou também que nas condições de pesquisa, o valor de $\mathrm{pH}$ aumentou entre o $19^{\circ}$ e o $43^{\circ}$ dias de estocagem, o que coincidiu com os dados de avaliação sensorial das características físicas, cujos resultados demonstraram acentuada perda de qualidade, passando de "boa qualidade" para "qualidade de consumo corrente". Nesta pesquisa, observou-se que o pH aumentou, passando de 6,24 a 6,34 quando a ava- liação sensorial física indicou mudança de qualidade, ou seja, quando os espécimes de matrinxãs passaram de "qualidade especial" para "boa qualidade", respectivamente. Não houve variação significativa quando passaram de "boa qualidade" para "qualidade de consumo corrente”.

Na equação da reta mostrada na Figura 5 que relaciona as variáveis "pH" e o "tempo de estocagem", esperava-se na curva de $\mathrm{pH}$ que, para cada dia que os exemplares de matrinxãs fossem mantidos em gelo, um aumento no valor de 0,01 ( $\mathrm{t}=4,29 ; \mathrm{p}=0,002)$. Os valores de $\mathrm{pH}$ determinados no músculo de matrinxã ajustaram-se numa regressão linear simples, com coeficiente de correlação elevado $(r=0,81)$ e nível de significância $(p=0,002)$ para o modelo utilizado. Baseado nestas observações, pode-se afirmar que este instrumento de avaliação se mostrou adequado para avaliar a qualidade de matrinxã conservado em gelo durante 29 dias de estocagem, nas condições experimentais.

\section{6 - Análise do Nitrogênio das Bases Voláteis To- tais (N-BVT)}

A determinação de N-BVT no músculo de matrinxã Brycon cephalus (Günther, 1869) procedente da piscicultura e mantido em gelo foi realizada no $16^{\circ}$ dia e no $29^{\circ}$ dia de conservação. Com 16 dias de estocagem em gelo, essa espécie apresentou quantidade média de $\mathrm{N}$-BVT igual a $19,0 \mathrm{mg} / 100 \mathrm{~g}$ de músculo $( \pm 0,9)$. O pH foi de $6,24( \pm 0)$ e as avaliações sensoriais (física gustativa) revelaram que o peixe estava em boa qualidade (classe B) e em qualidade especial (classe A), respectivamente. A quantidade de N-BVT aumentou no 29ำ dia atingindo valor médio de $33,3 \mathrm{mg} / 100 \mathrm{~g}$ de músculo $( \pm 0,3)$ e o pH determinado foi de $6,37( \pm 0)$. O Código Sanitário do Estado de São Paulo [27] estabelece o limite máximo de 30,0mg de N-BVT/100g de músculo de peixe fresco. Portanto, no $29^{\circ}$ dia de estocagem dos peixes em gelo, o resultado obtido nesta pesquisa é concordante com as avaliações sensoriais realizadas demonstrando que os peixes foram considerados impróprios para o consumo, neste mesmo período de estocagem. Alguns autores têm citado que esta determinação não se mostra um bom índice de avaliação da qualidade, porque apresenta inicialmente quantidades muito elevadas de N-BVT. No entanto, outros autores citam que isto se atribui à ação enzimática que ocorre no músculo e, principalmente pela quantidade de bactérias presentes capazes de produzir compostos nitrogenados, como amônia e aminas voláteis, que levam à deterioração do pescado mais rapidamente. HUSS [15] cita que os valores de N-BVT não devem ser utilizados para estimar as primeiras alterações e somente para avaliar o grau de deterioração nas últimas etapas de conservação. Esta afirmação tem sido válida para pescado procedente de mar e, também para pescado de rios e que são manejados inadequadamente. Porém, para peixes procedentes de piscicultura no Amazonas, esse índice tem se mostrado excelente para avaliação das alterações da qualidade. 


\section{7 - Análise bacteriológica}

Na Figura 6, podem ser observados os resultados das análises bacteriológicas realizadas na pele de matrinxã Brycon cephalus (Günther, 1869), procedente da piscicultura e conservado em gelo. $\mathrm{O}$ grupo de bactérias mesófilas a $35^{\circ} \mathrm{C}$ apresentou crescimento discreto ao longo de todo o período de estocagem dos peixes em gelo, passando de $4,6 \times 10^{3} \mathrm{UFC} / \mathrm{cm}^{2}$ no primeiro dia para $3,0 \times 10^{5} \mathrm{UFC} / \mathrm{cm}^{2}$ no vigésimo nono dia de estocagem. A legislação do Estado de São Paulo, através do seu Código Sanitário [27], estabelece o limite máximo de 3,0x10 6 UFC/g de pescado na contagem padrão em placa.

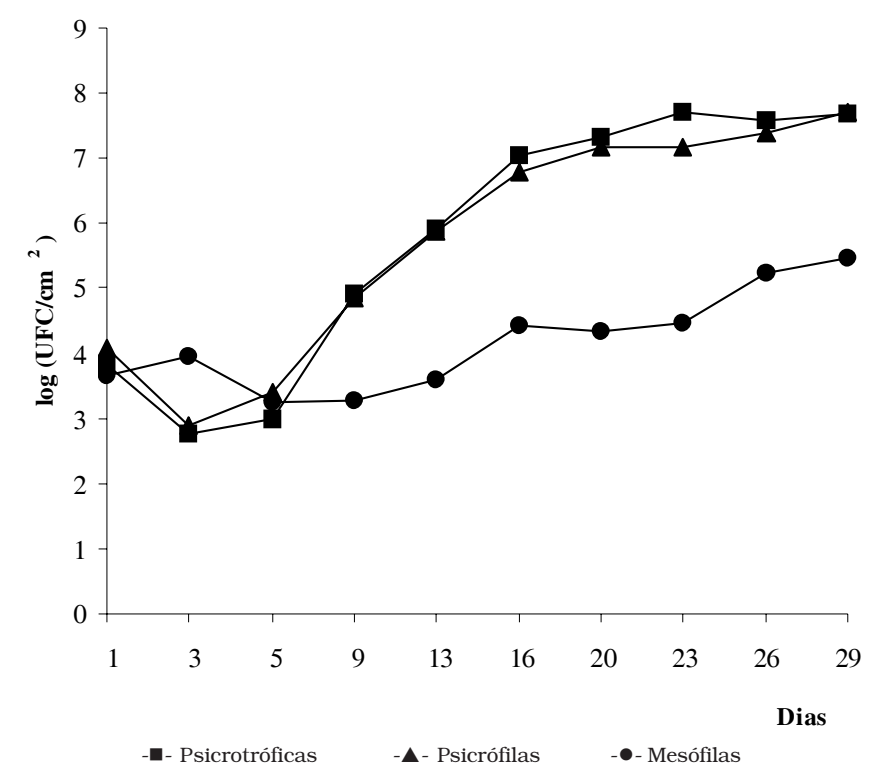

FIGURA 6. Contagem bacteriológica na pele de matrinxã Brycon cephalus (Günther, 1869) procedente da piscicultura, mantido em gelo durante 29 dias em Manaus AM.

De acordo com este parâmetro, o pescado continuava em condições de consumo no vigésimo nono dia de estocagem, sugerindo que esta classe de bactérias não é a deterioradora do pescado tropical de água doce. Por outro lado, os grupos de bactérias psicrotróficas $\left(7^{\circ} \mathrm{C}\right)$ e psicrófilas $\left(20^{\circ} \mathrm{C}\right)$ apresentaram comportamento diferente das mesófilas $\left(35^{\circ} \mathrm{C}\right)$. Na mesma Figura 6 , as bactérias psicrotróficas e psicrófilas que apresentaram valores iniciais de $6,7 \times 10^{3} \mathrm{UFC} / \mathrm{cm}^{2}$ e $1,2 \times 10^{4} \mathrm{UFC} / \mathrm{cm}^{2}$, respectivamente, mostraram redução no número até o quinto dia de estocagem dos peixes em gelo; apresentando, a partir daí, valores crescentes e semelhantes entre si, atingindo os valores de $4,9 \times 10^{7} \mathrm{UFC} / \mathrm{cm}^{2} \mathrm{de}$ psicrotróficas e $5,0 \times 10^{7} \mathrm{UFC} / \mathrm{cm}^{2}$ de psicrófilas aos vinte e nove dias de estocagem.

Segundo a avaliação sensorial física, a qualidade dos peixes saiu da classe A (especial) para classe B (boa qualidade), após 16 dias de estocagem. As bactérias psicrotróficas já tinham atingido $1,1 \times 10^{7} \mathrm{UFC} / \mathrm{cm}^{2}$ e as psicrófilas $6,2 \times 10^{6} \mathrm{UFC} / \mathrm{cm}^{2}$. A partir desse ponto, parece indicar uma estabilização no crescimento des- sas bactérias. Analisando os valores da avaliação sensorial gustativa, observou-se que somente no vigésimo terceiro dia de estocagem, os peixes mudaram de "qualidade especial" para "boa qualidade", indicando que o produto ainda estava em condições de consumo, apresentando os seguintes valores: contagem total de $5,0 \times 10^{7} \mathrm{UFC} / \mathrm{cm}^{2}$ para psicrotróficas e contagem total de $1,5 \times 10^{7} \mathrm{UFC} / \mathrm{cm}^{2}$ para psicrófilas.

HUSS [16] cita que uma grande parte das bactérias presentes no pescado deteriorado não desempenha nenhum papel no processo de deterioração. Cada produto pesqueiro possui suas próprias bactérias específicas de deterioração, e é o número dessas bactérias e não o número total de microrganismos que estabelece relação com a duração do tempo de estocagem do produto. Apesar de que os peixes apresentaram contagens de bactérias psicrotróficas e de psicrófilas acima de $10^{6} \mathrm{UFC} / \mathrm{cm}^{2}$ após 16 dias de estocagem em gelo, estes grupos de bactérias participaram muito mais do processo de deterioração dos espécimes de matrinxãs do que o grupo de bactérias mesófilas.

\section{8 - Análise de ATP e seus produtos de degradação}

A Figura 7 apresenta os resultados obtidos da determinação de ATP e dos produtos de degradação de ATP em músculo de matrinxã Brycon cephalus (Günther, 1869) procedente de piscicultura e mantido em gelo. Os valores médios de ATP se mantiveram baixos no início do experimento $(<0,2 \mu \mathrm{moles} / \mathrm{g})$ e permaneceram assim até o 23o dia de análise; ao passo que os valores médios de $\mathrm{ADP}$, após a morte dos peixes, foram de $0,31 \mu$ moles/g $( \pm 0)$, aumentou para $0,37 \mu$ moles $/ g( \pm 0)$ com 30 minutos e decresceu lentamente até atingir zero após 1 dia de estocagem. Os valores de AMP apresentaram inicialmente $(\mathrm{Oh})$ média de $0,94 \mu$ moles/g $( \pm 0)$ e decresceram após 30 minutos de conservação em gelo, alcançando quantidade média de $0,13 \mu$ moles/g $( \pm 0)$.

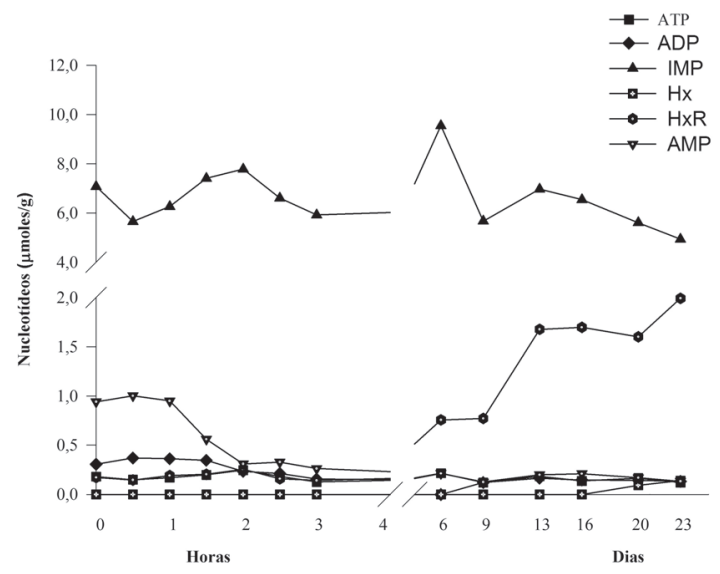

FIGURA 7. Determinação da concentração de nucleotídeos em músculo de matrinxã Brycon cephalus (Günther, 1869) procedente da piscicultura, mantido em gelo durante 23 dias em Manaus - AM.

O músculo de matrinxã apresentou quantidade muito elevada de IMP que variou ao longo da pesquisa. 
Os valores médios de IMP logo no início (Oh) foram de $7,08 \mu$ moles/g $( \pm 1,2)$, alcançando limite máximo de $9,54 \mu$ moles $/ g( \pm 0,9)$ com 6 dias de estocagem. Somente após o $13^{\circ}$ dia, a espécie apresentou redução gradual no conteúdo de IMP, alcançando quantidade média de $4,94 \mu$ moles/g $( \pm 0,5)$ no $23^{\circ}$ dia de estocagem.

No início do experimento, os exemplares de matrinxãs foram capturados com uma rede de pesca pequena, longe da margem do viveiro. Após a captura, os peixes foram colocados em sacos de fibra e transportados, ainda vivos, lentamente sobre a água do canal da barragem, até que pudessem ser sacrificados por hipotermia. Acredita-se que esses procedimentos possam ter contribuído para acelerar a degradação de ATP e aumentar rapidamente a quantidade de IMP no músculo dos peixes.

Segundo KASSEMSARN et al. [20], UCHIYAMA e EHIRA [28] em músculo de peixe após a morte, a degradação de ATP para IMP via ADP e AMP ocorre rapidamente, enquanto que de IMP para HxR e Hx ocorre mais lentamente, resultando numa extensa formação de IMP no período inicial de estocagem. Fenômeno semelhante ocorreu com as amostras de matrinxãs estocadas em gelo nesta pesquisa.

A degradação de IMP, acumulado no músculo de matrinxã, para HxR ocorreu lentamente e somente após 6 dias de estocagem a espécie apresentou redução gradual no conteúdo de IMP. Sendo assim, a concentração de HxR aumentou após 6 dias de conservação em gelo, muito mais do que $\mathrm{Hx}$, um nucleotídeo que apresenta sabor amargo e é considerado como bom índice de qualidade de pescado de água doce e de água marinha por muitos autores.

Segundo EHIRA e UCHIYAMA [11], o peixe é definido como produtor de inosina quando a razão de inosina para hipoxantina é de 5:1 e produtor de hipoxantina quando essa razão é de 1:5. Alguns autores citam que a hipoxantina produzida em peixe tem sido usada como índice de avaliação do frescor, porém os resultados obtidos com os espécimes de matrinxãs de criatório desta pesquisa não concordam com esta afirmação. EHIRA [12] cita que alguns peixes, como o "horse mackerel" (Trachurus japonicus) acumulam HxR, enquanto que outros, como o "flatfish", acumulam Hx.

Os resultados apresentados na Figura 7 mostram que a espécie Brycon cephalus pode ser considerada como "formadora de inosina", como principal produto de degradação de IMP, acumulada durante 23 dias de estocagem em gelo. Foi verificado que a quantidade de hipoxantina não se mostrou adequada para avaliar o frescor de matrinxã.

\section{9 - Análise do valor $K$}

Os resultados obtidos da determinação do valor $\mathrm{K}$ apresentados na Figura 8 mostraram que no primeiro dia de experimentação os espécimes de matrinxãs não apresentaram grande variação para esse índice, variando de $2,01 \%( \pm 0,5)$ a $3,29 \%( \pm 0)$. Com três dias de estoca- gem, este índice atingiu 5,86\% $( \pm 0,3)$; somente após 16 dias de estocagem, o valor K alcançou $19,56 \%( \pm 0)$, portanto inferior a $20 \%$ que é o limite estabelecido por OKUMA et al. [25] para peixe muito fresco, podendo ser consumido cru. Neste mesmo período de 16 dias, o valor médio de $\mathrm{pH}$ foi de $6,24( \pm 0)$ e a quantidade média de N-BVT foi de $19,6 \mathrm{mg} / 100 \mathrm{~g}$ de músculo $( \pm 0,9)$. No entanto, as determinações bacteriológicas demonstraram contagens de $1,1 \times 10^{7} \mathrm{UFC} / \mathrm{cm}^{2}$ para psicrotróficos totais e $6,2 \times 10^{6} \mathrm{UFC} / \mathrm{cm}^{2}$ para psicrófilos totais (Figura 6).

A avaliação sensorial física indicou que os peixes estavam entrando na classe B "boa qualidade" e a avaliação sensorial gustativa indicou que os peixes permaneceram com classe A "qualidade especial", [Figuras 3 e 4]. Com 20 dias de estocagem, os peixes apresentaram média do valor $K$ igual a $21,21 \%( \pm 0,9)$, considerado fresco e de acordo com os critérios das avaliações sensoriais (física e gustativa), os peixes permaneciam em "boa qualidade" e "qualidade especial", respectivamente. Com 23 dias de estocagem em gelo, o valor $\mathrm{K}$ determinado e as avaliações sensoriais realizadas mostraram concordância no critério de avaliação do frescor, onde o valor $\mathrm{K}$ alcançou média de $28,87 \%( \pm 0,6)$, considerado fresco e pelas avaliações sensorias os peixes foram classificados com "boa qualidade" (Classe B).

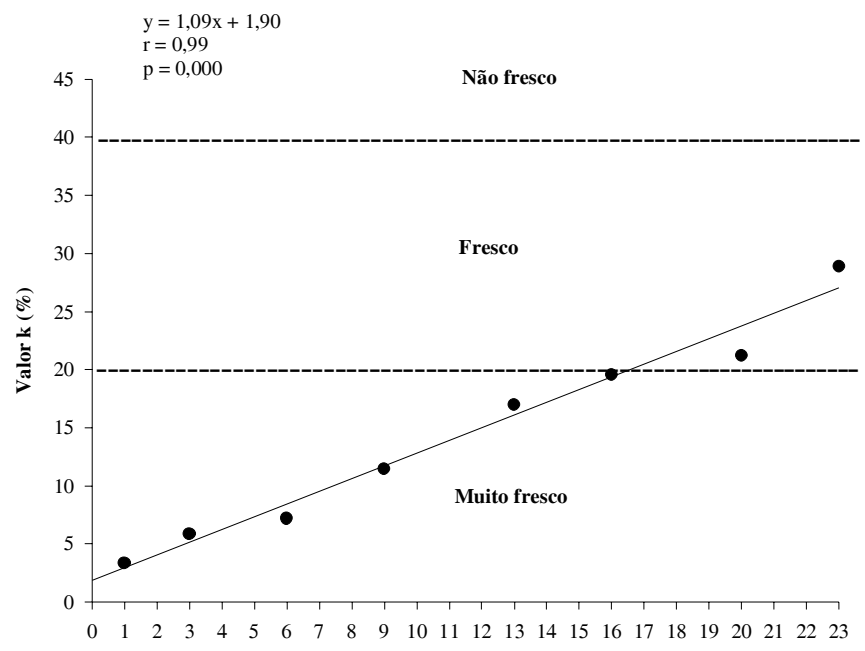

Dias

FIGURA 8. Determinação do valor $\mathrm{K}$ de matrinxã Brycon cephalus (Günther, 1869) procedente da piscicultura, mantido em gelo durante 23 dias em Manaus-AM.

A quantidade de IMP e o valor K são usados como critérios de qualidade para determinar o limite de consumo para "sashimi" (produto preparado de peixe cru). EHIRA [12] estabeleceu o valor K de $20 \%$ como o limite máximo para o consumo de peixe cru.

Nesta pesquisa, observou-se que a desfosforilação de IMP ocorreu lentamente no músculo de matrinxã e apresentou quantidades elevadas até 13 dias de estocagem em gelo. Foi seguido o limite estabelecido por OKUMA et al. [25] que consideram o pescado "muito fresco" quando o valor K alcança até $20 \%$, "fresco" quan- 
do o valor K alcança entre 20 e $40 \%$ e "não fresco" quando o valor $\mathrm{K}$ é maior do que $40 \%$. Portanto, em se tratando de peixe de água doce e sendo de piscicultura, a espécie Brycon cephalus (Günther, 1869) foi considerada fresca com 23 dias de estocagem em gelo apresentando quantidade de IMP igual a $4,9 \mu$ moles/g de músculo e quantidade de HxR igual a 2,0 $\mu$ moles/g de músculo.

Na equação da reta demonstrada no gráfico da Figura 8, que relaciona as variáveis "valor $\mathrm{K}$ " e o "tempo de estocagem”, esperava-se na curva $K$ que, para cada dia que os exemplares de matrinxãs fossem mantidos em gelo, um aumento no valor de 1,90 ( $\mathrm{t}=4,29 ; \mathrm{p}=0,000)$. Os valores K determinados no músculo de matrinxã ajustaram-se numa regressão linear simples, com coeficiente de correlação linear elevado $(r=0,99)$ e nível de significância ( $p=0,000$ ) para o modelo utilizado. Baseado nessas observações é lícito mencionar que o valor $\mathrm{K}$ se mostrou adequado para avaliar o frescor dos espécimes de matrinxãs procedentes da piscicultura e conservados em gelo.

\section{4 - CONCLUSÕES}

O índice de rigor determinado nos espécimes de matrinxãs, procedentes da piscicultura, sacrificados por hipotermia e conservados em gelo, mostrou que o rigormortis ocorreu aos 75 minutos e permaneceu durante 10 dias.

As avaliações sensoriais físicas e gustativas, nos espécimes de matrinxãs apresentaram "qualidade de consumo" durante 26 dias de estocagem em gelo, sendo que durante 13 dias se mantiveram com classe $\mathrm{A}$ "qualidade especial".

Nas condições experimentais do presente trabalho, a determinação de $\mathrm{pH}$ pode ser considerada um bom índice de avaliação do frescor.

As bactérias psicrotróficas e psicrófilas tiveram maior participação do processo de deterioração de matrinxã mantido em gelo do que as bactérias mesófilas.

As determinações de ATP e seus compostos degradados mostraram que o matrinxã pode ser considerado formador de HxR (inosina) e não de Hx (hipoxantina).

$\mathrm{O}$ valor $\mathrm{K}$ determinado durante 23 dias de estocagem mostrou boa correlação com o tempo de estocagem $(\mathrm{r}=0,99)$, de acordo com as avaliações sensoriais físicas e gustativas, sendo considerado bom índice de avaliação de frescor para espécimes de matrinxãs estocados em gelo.

\section{5 - REFERÊNCIAS BIBLIOGRÁFICAS}

[1] ACKMAN, R.G. Nutritional composition of fats in seafoods. Progr. Food Nutr. Sci., v. 13, p. 161-241, 1989.

[2] ALMEIDA, N.M. Alterações post-mortem em Colossoma macropomum (Cuvier, 1818), procedente da piscicultura e conservado em gelo. Manaus, 1998, 90p. Dissertação (Mestre em Ciência de Alimentos), Facul- dade de Ciências da Saúde. Universidade Federal do Amazonas (UFAM).

[3] AMLACHER, E. Rigor mortis in fish. In: BORGSTROM, G. (Ed.) Fish as Food. New York: Academic Press, 1961. Cap. 12, p. 385-409.

[4] ASSOCIATION OF OFFICIAL ANALYTICAL CHEMISTS. Official Methods of Analysis. 15 a ed. Washington, 1990. 960p.

[5] BATISTA, I.; NUNES, M.L. Manuseamento do pescado. Lisboa: INIP, 1993. 53p. (Publicações avulsas do INIP, n. 20).

[6] BITO, M.; YAMADA, K.; MIKUMO, Y.; AMANO, K. Studies on rigor mortis of fish - I. Difference in the mode of rigor mortis among some varieties of fish by modified Cutting's method. Bull. Tokai Reg. Fish. Res. Lab., n. 109, p. 89-96, 1983.

[7] BURGESS, G.H.O.; CUTTING, C.L.; LOVERN, J.A.; WATERMAN, J.J. Fish Handling \& Processing. In: BURGESS, G.H.O.; CUTTING, C.L.; LOVERN, J. A.; WATERMAN, J.J. (Ed.) Fish spoilage. New York: Chemical Publishing Company, 1967. Cap. 15, p. 346356.

[8] __ El pescado y las industrias derivadas de la pesca. In: Alteración del pescado. Zaragoza: Acribia, 1987. Cap. 15, p. 354-364.

[9] CHATTERJEe, S.; PRICE, B. Regression Analysis by Example, $2^{a}$ edição. New York: JOHN WILEY \& SONS, 1991.

[10] CURRAN, C.A.; POUlten, R.G.; BRUEton, A.; JONES, N.S.D. Cold shock reactions in iced tropical fish. J. Food Technol., v. 21, n. 3, p. 289-299, 1986.

[11] EHIRA, S.; UCHIYAMA, H. Formation of inosine and hypoxanthine in fish muscle during ice storage. Bull. Tokai Reg. Fish. Res. Lab., n. 75, p. 63-73, 1973.

[12] EHIRA, S. A biochemical study on the freshness of fish. Bull. Tokai Reg. Fish. Res. Lab., n. 88, p. 1-132, 1976.

[13] FALCÃO, P.T., LESSI, E., LEITÃO, M.F.F. Deterioração do jaraqui (Semaprochilodus. insignis, Schombugk, 1841) capturado no estado do Amazonas e conservado em gelo. Ciênc. Tecnol. Alim. v. 14, n. 4, p. 168-177, 1994.

[14] FAO/DANIDA Curso de tecnologia e controle de qualidade de produtos de pesca: relatório. Moçambique, 1987. 74p.

[15] HUSS, H.H. Fresh fish: quality and quality changes. Rome: FAO: DANIDA, 1988. 132p. (FAO Fisheries Series, n. 29).

[16] HUSS, H.H. El pescado fresco: su calidad y cambios de su calidad. Rome: FAO, 1998. 202p. (Documento Tecnico de Pesca, n. 348).

[17] INSTITUTO ADOLFO LUTZ. São Paulo. Normas Analíticas do Instituto Adolfo Lutz. $3^{\text {a }}$ ed., São Paulo, 1985, v. $1,533 p$.

[18] IWAMOTO, M.; YAMANAKA, H.; WATABE, S.; HASHIMOTO, K. Effect of storage temperature on rigor-mortis and ATP degradation in plaice (Paralichthys olivaceus) muscle. J. Food Sci., v. 52, n. 6, p. 15141518,1987

[19] IWAMOTO, M.; YAMANAKA, H.; ABE, H.; USHIO, H.; WATABE, S.; HASHIMOTO, K. ATP and creatine phosphate breakdown in spiked plaice muscle during storage, and activities of some enzymes involved. J. Food Sci., v. 53, n. 6, p. 1662-1665, 1988.

[20] KASSEMSARN, B.; PEREZ, B.S.; MURRAY, J.; JONES, N.R. Nucleotide degradation in the muscle of iced 
haddock (Gadus aeglefinus), lemon sole Pleuronectes platessa). J. Food Sci., v. 28, n. 1, p. 28-37, 1963.

[21] KODAIRA, M. Manejo del pescado de agua continentales en condiciones de refrigeración. FAO Informe de Pesca, Roma, n. 476, p. 104-128, 1994. Suplemento.

[22] LEITÃO, M.F.F.; TEIXEIRA FILHO, A.R.; BALDINI, V.S. Microbiota bacteriana em espécies de peixes fluviais e lacustres no Estado de São Paulo. Colet. Inst. Tecnol. Alim., Campinas, v. 15, p. 91-111, 1985.

[23] LESSI, E.; KODAIRA, M.; BATISTA, G.M.; BELLO, R. Cambios post-mortem del matrinxã Brycon cephalus (Günther, 1869), cultivado en Manaus, Brasil. In: II CONGRESO VENEZOLANO DE CIENCIA Y TECNOLOGIA DE ALIMENTOS “DR ASHER LUDIN”, Caracas, 1999. Programa e Resumos. Caracas: UCV, 1999. p. 114.

[24] NAMBUDIRI, D.D.; GOPAKUMAR, K. Cold Shock reactions in tropical fishes. J. Food Sci. Technol., v. 25, n. 2, p. 89-91, 1988.

[25] OKUMA, H.; TAKAHASHI, H.; YAZAWA, S.; SEKIMUKAI, $\mathrm{S}$. Development of a system with double enzyme reactors for the determination of fish freshness. Anal. Chim. Acta, v. 260, p. 93-98, 1992.
[26] SAITO, T.; ARAI, K.; MATSUYOSHI, M. A new method for estimating the freshness of fish. Bull. Jpn. Soc. Sci. Fish. v. 24, n. 9, p. 749-750, 1959.

[27] SÃO PAULO (Estado). Código Sanitário do Estado de São Paulo. São Paulo: IMESP, 1991. 412p.

[28] UCHIYAMA, H.; EHIRA, S. Relation between freshness and acid-soluble nucleotides in aseptic cod and yellowtail muscles during ice storage. Bull. Tokai Reg. Fish. Res. Lab., n. 78, p. 23-31, 1974.

[29] VALLS, J.; BELLO, R.; KODAIRA, M. Validation of liquid chromatography analysis od ATP-related compounds in sardine. J. Aquat. Food Product Technol., v. 10, n. 3, p. 67-79, 2001.

\section{6 - AGRADECIMENTOS}

Ao projeto CNPq/PTU/INPA/CPTA no 469909/00-5 "Uso de Recursos Pesqueiros de Águas Continentais da Bacia Amazônica no Desenvolvimento de Produtos com Valor Agregado para Transferência de Tecnologia”, por ter financiado a pesquisa. 